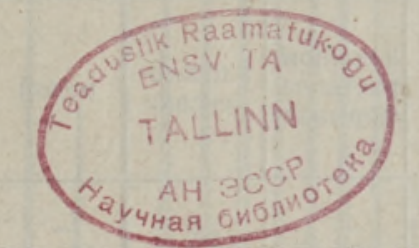

Лиа НАППА, И. КЛЕСМЕНТ, Наталья ВННК

\title{
ГИДРОГЕНИЗАЦИЯ И КОНВЕРСИЯ БОЛГАРСКОГО СЛАНЦА МЕСТОРОЖДЕНИЯ БОРОВ ДОЛ
}

Из горючих сланцев, распространенных на территории Болгарской НР, промышленный интерес представляют сланцы месторождения Боров Дол Сливенского округа. Характеристики месторождения, самих сланцев и их битумондов представлены в ['].

Термическую деструкцию проводили с пробой следующего состава,

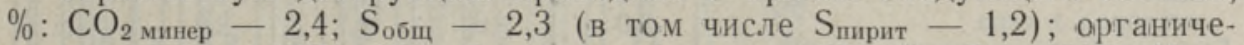
ское вещество (ОВ) 22,0. Элементный состав ОВ, \%: С $-61,8 ; \mathrm{H}-$ 9,$6 ; \mathrm{N}-2,2 ; \mathrm{S}-0,8 ; \mathrm{O}-25,6$. Атомное отношение $\mathrm{H} / \mathrm{C}$ высокое, но при полукоксовании много водорода расходуется на гидрогенолитическое отщепление кислорода, которого так же много, как и в малопревращенных углях. Выход битумондов, \%: А 2,$1 ; \mathrm{C}-5,2$ [']. Гидрогенизацию и конверсию проводили в автоклаве, полукоксование - в лабораторной реторте по ГОСТу 3168-66.

Техника проведения автоклавных опытов, соотношение сланца и растворителя, а также нанесение Мо-катализатора описаны в [ $\left.{ }^{2}\right]$. Каталитическую гидрогенизацию проводили в среде циклогексана. При комнатной температуре полученные смолы имели твердую консистенцию. Их разделение и анализ осуществляли по общепринятой методике [3].

Самый низкий выход смолы получается при полукоксовании $(28 \%)$. При конверсии водой он остается 'на таксм же уровне, а при добавлении щелочи доходит до $43 \%$. При гидрогенизации в водном растворе формиата натрия, когда высвобождающийся при разложении формиата водород вступает в реакцию с керогеном сланца, образуется до $49 \%$ смолы. Самый высокий выход смолы получался при каталитической гидрогенизации в среде циклогексана. При термической деструкции образуется около $30 \%$ газа, причем при полукоксовании и конверсии с повышенным содержанием двуокиси углерода и метана,

, Состав газов, низкий выход смолы полукоксования и элементный состав ОВ указывают на большую долю гумусового материала в сланце. Полученные смолы, как и смолы из сланца месторождения Мандра [ $\left.{ }^{2}\right]$, характеризуются чрезвычайно высоким содержанием парафинов, особенно в смоле полукоксования (79\%). В других смолах, выход которых увеличивался за счет гидрогенизации гумусового материала, относительное содержание парафинов меньше. Они были выделены из смол в виде карбамидных комплексов, но групповой анализ депарафинированных смол показывает, что парафинов в них осталось еще около $11-18 \%$.

Следует учитывать также, что карбамид извлекает часть $\mu$-кетонов, поэтому данные по содержанию н-парафинов - в табл. 1 могут быть немного завышенными. 
Выходы и характеристика продуктов термической деструкции болгарского горючего сланца месторождения Боров Дол (температура $370^{\circ} \mathrm{C}$; время 3 ч)

\begin{tabular}{|c|c|c|c|c|c|}
\hline \multirow[b]{2}{*}{ Показатели } & \multirow[b]{2}{*}{$\begin{array}{l}\text { Полу: } \\
\text { коксо- } \\
\text { вание }\end{array}$} & \multicolumn{2}{|c|}{ Гидрогенизация } & \multicolumn{2}{|c|}{ Конверсия } \\
\hline & & $\begin{array}{l}\text { в водном } \\
\text { растворе } \\
\text { формиата }\end{array}$ & $\begin{array}{l}\text { в цикло- } \\
\text { гексане }\end{array}$ & водой & $\begin{array}{c}5 \% \text {-ным } \\
\text { водным } \\
\text { раство- } \\
\text { ром } \\
\mathrm{NaOH}\end{array}$ \\
\hline $\begin{array}{l}\text { Первоначальное давление, МПа } \\
\text { Рабочее давление, МПа } \\
\text { Остаточное давление, МПа } \\
\text { Выходы на ОВ, вес.\%: } \\
\text { смола } \\
\text { кокс. } \\
\text { вода разложения, газ и потери } \\
\text { Характеристика смолы: } \\
\text { плотность } \\
\text { показатель преломления } \\
\text { Элементный состав, вес. \%: } \\
\text { углерод } \\
\text { водород } \\
\text { азот } \\
\text { кислород и сера } \\
\text { Групповой состав смолы, вес. \%: } \\
\text { алифатические углеводороды } \\
\text { алкилароматические } \\
\text { полициклические ароматические } \\
\text { углеводороды } \\
\text { кислородсодержащие соединения } \\
\text { высокополярные гетероатомные } \\
\text { соединения }\end{array}$ & $\begin{array}{c}- \\
- \\
28 \\
40 \\
32 \\
0,892 \\
1,497 \\
84,0 \\
12,0 \\
1,0 \\
3,0 \\
79 \\
3,1 \\
3,8 \\
5,4 \\
8,7\end{array}$ & $\begin{array}{l}3 \overline{3} \\
2,7 \\
49 \\
21 \\
30 \\
0,917 \\
1,511 \\
83,0 \\
10,5 \\
1,9 \\
4,6 \\
45 \\
9 \\
11 \\
13 \\
22\end{array}$ & $\begin{array}{c}2,2 \\
12,0 \\
1,6 \\
56 \\
36 \\
8 \\
0,892 \\
1,499 \\
85,2 \\
11,4 \\
1,2 \\
2,2 \\
65 \\
5 \\
6 \\
7 \\
17\end{array}$ & $\begin{array}{c}25 \\
0,4 \\
28 \\
38 \\
34 \\
0,850 \\
1,460 \\
84,0 \\
12,0 \\
1,1 \\
2,9 \\
34 \\
10 \\
12 \\
13 \\
\\
.31\end{array}$ & $\begin{array}{c}30 \\
1,8 \\
43 \\
27 \\
30 \\
0,981 \\
1,545 \\
82,8 \\
10,5 \\
1,7 \\
4,5 \\
46 \\
6 \\
11 \\
13 \\
24\end{array}$ \\
\hline
\end{tabular}

Групповой состав смол рассчитывали, учитывая количество выделенных карбамидом парафинов и групповой состав депарафинированных смол (см. табл. 1). В смоле полукоксования ароматических и гетеросоединений немного, а. в других смолах, по вышеприведенным причинам, их больше, особенно высокополярных гетеросоединений.

Хроматографический анализ показывает, что длинноцепочечные $\boldsymbol{H}$-парафины смол сланца Боров Дол представлены от $\mathrm{C}_{9}$ до $\mathrm{C}_{30}$, тогда как в смолах сланца Мандра цепи н-парафинов достигали $\left.\mathrm{C}_{37}{ }^{2}\right] . \mathrm{Ha}$ хроматограмме парафинов смолы полукоксования (рис. 1) видны пики $\boldsymbol{H}$-парафинов, $\boldsymbol{H}$-олефинов и разветвленных парафинов. В процессе гидрогенизации $н$-олефинов не образуется, а в смолах конверсии они присутствуют в виде следов. Моноциклические ароматические соединения представлены гомологическим рядом алкилбензолов, во фракциях полициклических ароматических соединений идентифицированы нафталин, метил- и диметилнафталины, дифенил, флуорен, антрацен, фенантрен. Кислородсодержащие соединения представлены гомологическим рядом кетонов от $\mathrm{C}_{10}$ до $\mathrm{C}_{30}$. Судя по хроматограмме фракции кислородсодержащих соединений (рис. 2), в смоле конверсии присутствуют метилкетоны, а также изомеры с центральным расположением карбонильной группы. Если в продуктах термической деструкции кукерсита преобладают метилкетоны [4], то в продуктах конверсии болгарских сланцев доминируют кетоны с карбонильной группой в центральном положеңии, отмечается чрезвычайно высокая концентрация нечетных метилкетонов, как и при конверсии кукерсита [ $\left.{ }^{4}\right]$.

${ }^{1}$ Н-ЯМР-спектры показывают (рис. 3), что смолы термической деструкции характеризуются малой ароматичностью (сигналы в интер- 


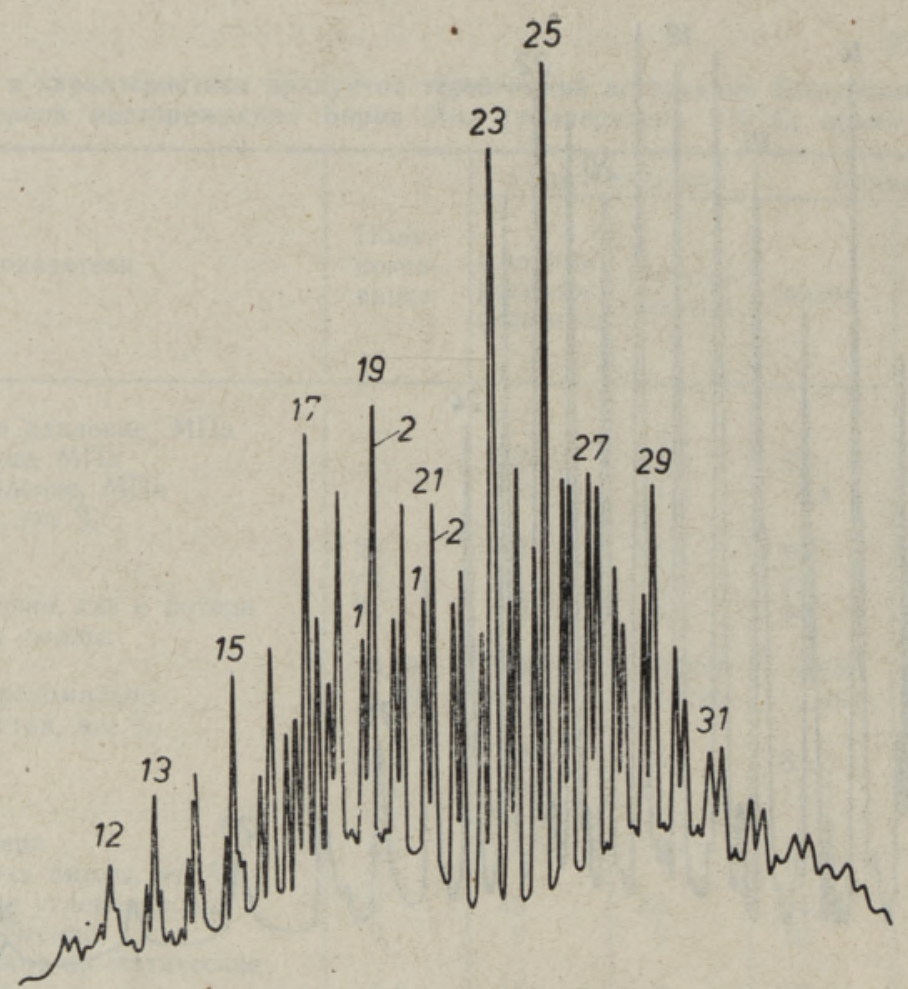

Рис. 2. Хроматограмма кетонов смолы конверсии. 12-31 -число атомов углерода в молекуле: 1 - кетоны с карбонильной группой в центральном положении, 2 - метилкетоны.

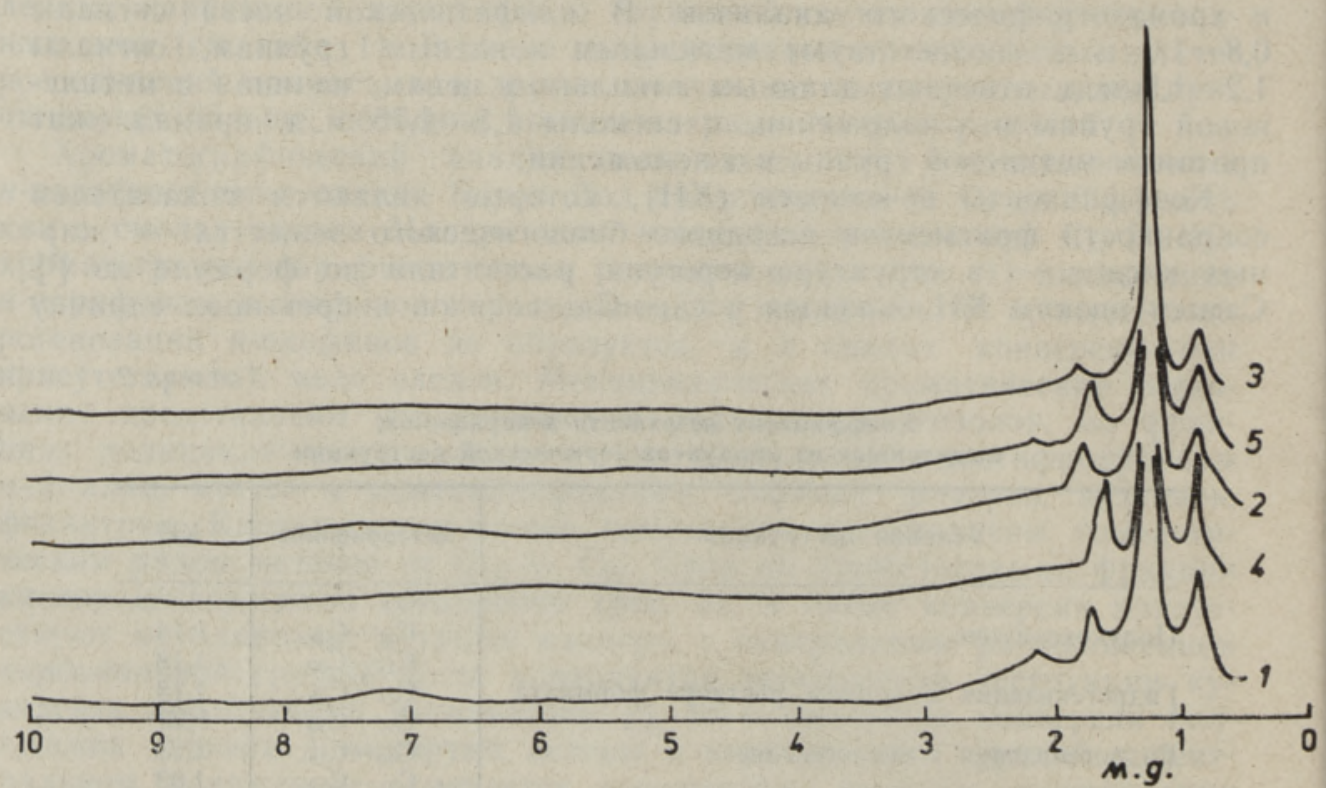

Рис. 3. 'Н-ЯМР-спектры смол термической деструкции: 1 - полукоксование, 2 гидрогенизация в водном растворе формиата, 3 - гидрогенизация в циклогексане, 4 - конверсия водой, 5 - конверсия водным раствором ще́лочи. 
$(1,14)$, с ростом цепи $\mathrm{KH}$ увеличивался и у $\mathrm{C}_{13}-\mathrm{C}_{29}$ доходил до 1,28 (табл. 2). При керогенообразовании кислоты, имеющие четное число углеродных атомов, декарбоксилируются [ $\left.{ }^{6}\right]$. При деструкции образовавшиеся парафины имеют нечетное число атомов углерода [7]. Повышенный КН парафинов гидрсгенизата и смолы полукоксования показывает, что при диагенезе ОВ глубоких процессов превращения (в том числе и бактериальных) не происходило и что при деструкции керогена вторичных реакций не было, отчего и сохранились исходные структуры биологического вещества.

Самое характерное для сланца месторождения Боров Дол - высокое содержание парафинов в смолах термической деструкции при относительно низком выходе смолы полукоксования. Высокая парафинистость смолы полукоксования отмечена также в [ $\left.{ }^{8}\right]$. Выход смолы увеличивается при водной конверсии и почти удваивается при каталитической гидрогенизации. Можно предположить, что если при гидрогенизации циклогексан заменить более высококипящим растворителем, в смолу превратится не менее $2 / 3$ ОВ.

Подобно сланцам Боров Дол деструктируются и исследованные

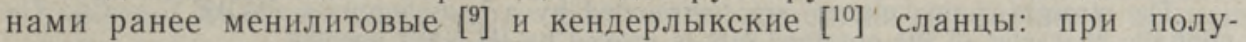
коксовании образуется мало смолы, при гидрогенизации - много. OB этих сланцев имеет различный состав, но высокое содержание гумусового вещества, свойственно, по-видимому, всем трем.

\section{ЛИТЕ Р А Т У Р А}

1. Клесмент Н., Куузик М., Побуль Л. Битуминологическая характеристика болгарского горючего сланща месторождения Боров Дол. - Изв. АН ЭССР. Хим., 1981, 30, № 2, $69-74$.

2. Наппа Л̆., Клесмент Н̈., Винк $H$., Кайлас К. Изучение органического вещества горючего сланца месторождения «Мандра» низкотемпературной деструктивной гидрогенизацией. - Изв. АН ЭССР. Хим., 1979, 28, № 3, 191-197.

3. Klesment, I. Application of chromatographic methods in biogeochemical investigations. - J. Chromatogr., 1974, 91, N 2, 705-713.

4. Klesment, I., Nappa, L. Investigation of the structure of Estonian oil shale kukersite by conversion in aqueous suspension. - Fuel, 1980, 59, 117-122.

5. Bray, E. E., Evans, E. D. Distribution of $n$-parafíns as a due to recognition of source beds. - Geochim, et Cosmochim. Acta, 1961, 22, N 1, 2-9.

6. Клесмент И. Алифатические структуры в керогене горючих сланцев. - В кн.: Исследование органического вещества современных и ископаемых осадков. M., 1976, 187-195.

7. Клесмент Н. Роль жирных кислот при образовании некоторых сапропелитов. В кн.: Органическое вещество современных и ископаемых осадков. М., 1974, $122-129$.

8. Развигорова М., Ангелова Г. Сравнительна характеристика на неутралних масла от полукоксоването на битуминозни скали от някоп находища в България. Нафтена и въглищна геология, 1979, № 10, 25-31.

9. Наппа Л., Клесмент Н., Винк Н. Исследование состава и генезиса карпатских менилитовых сланцев. 3. Гидрогенизация и конверсия. - Изв. АН ЭССР. Хим., 1982, 31, № 4, 292-295.

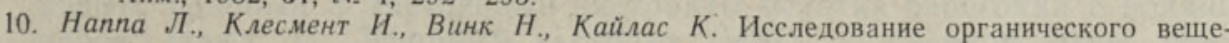
ства кендерлыкских горючих сланцев, 3. Низкотемпературная деструкция в автоклаве. - Изв. АН ЭССР. Хим., 1982, 31, № 3, 157-162.

Ннститут химии

Академии наук Эстонской ССР
Поступила в редакцию 10/III 1983 


\section{BULGAARIA BOROV DOLI LEIUKOHA POLEVKIVI HUDROGEENIMINE JA KONVERTEERIMINE}

Artiklis on kirjeldatud Bulgaaria põlevkivi termilist destruktsiooni. Kõige madalama õlisaagise annab utmine, konverteerimisel saagis suureneb, katalüütilisel hüdrogeenimisel isegi kahekordistub. Saadud ōlisid iseloomustab väga kõrge $n$-parafiinide $C_{9}-C_{30}$ sisaldus (utteōlis $79 \%$ ), mistōttu saadud õlid on toatemperatuuril tahked. Ketoonid on esindatud homoloogilise reana $\mathrm{C}_{10}-\mathrm{C}_{30}$. Olide alifaatset iseloomu kinnitavad ka ${ }^{1} \mathrm{H}$-TMR spektrid.

Lia NAPPA, I. KLESMENT, Natalija VINK

\section{HYDROGENATION AND CONVERSION OF BULGARIAN BOROV DOL OIL SHALE}

The thermal decomposition of Bulgarian oil shale is described. The lowest oil yield is obtained by semi-coking; by conversion the oil yield increases, and by catalytic hydrogenation it doubles. The obtained liquid products are characterized by a high straightchain $n$-paraffins $\mathrm{C}_{9}-\mathrm{C}_{30}$ content as a result of which the oils turn solid at room temperature.

The straight-chain ketones are represented by a homologous series of $\mathrm{C}_{10}-\mathrm{C}_{30}$. The aliphatic character of the obtained oils is proved by ${ }^{1} \mathrm{H}-\mathrm{NMR}$ spectra. 